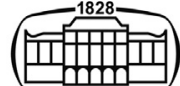

AKADÉMIAI KIADÓ

\title{
Effect of high temperatures on the efficiency of sub-critical $\mathrm{CO}_{2}$ cycle
}

\author{
Aram Mohammed Ahmed ${ }^{1,2 *} \odot$ and Attila R. Imre ${ }^{1,3}$
}

\section{Pollack Periodica • \\ An International Journal \\ for Engineering and Information Sciences}

16 (2021) 2, 73-79

DOI:

$10.1556 / 606.2021 .00310$

(c) 2021 The Author(s)
ORIGINAL RESEARCH PAPER

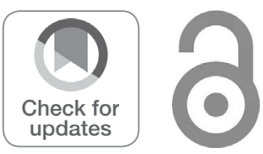

${ }^{1}$ Department of Energy Engineering, Faculty of Mechanical Engineering, Budapest University of Technology and Economics, Müegyetem rkp. 3, H-1111 Budapest, Hungary

${ }^{2}$ Technical College of Kirkuk, Northern Technical University, 36001 Kirkuk, Iraq

${ }^{3}$ Department of Thermohydraulic, Centre for Energy Research, POB. 49, H-1525 Budapest, Hungary

Received: December 1, 2020 • Revised manuscript received: January 10, 2021 • Accepted: January 12, 2021 Published online: April 23, 2021

\section{ABSTRACT}

Thermodynamic efficiency is a crucial factor of a power cycle. Most of the studies indicated that efficiency increases with increasing heat source temperature, regardless of heat source type. Although this assumption generally is right, when the heat source temperature is close to the critical temperature, increasing the heat source temperature can decrease efficiency. Therefore, in some cases, the increase in the source temperature, like using improved or more collectors for a solar heat source can have a double negative effect by decreasing efficiency while increasing the installation costs. In this paper, a comparison of the $\mathrm{CO}_{2}$ subcritical cycle and the Trilateral Flash Cycle will be presented to show the potential negative effect of heat source temperature increase.

\section{KEYWORDS}

subcritical carbon dioxide cycle, Trilateral Flash Cycle, critical temperature, heat source, maximum efficiency

\section{INTRODUCTION}

The demand for energy in the world increases; this increase is preferably satisfied by modern power plants using a clean, renewable source. A special class of these power plants is the one operated by low heat sources, using organic Rankine cycles or carbon dioxide power cycle. The transcritical $\mathrm{CO}_{2}$ power cycle (working with heat sink temperature below and heat source temperature above the critical temperature $\left(T_{c r}\right)$ of $\mathrm{CO}_{2}$, namely $\left.31{ }^{\circ} \mathrm{C}\right)$ has significant and sufficient potential to convert the heat to produce power (electricity) by using the carbon dioxide as a working fluid due to its good thermodynamic and environmental properties $[1,2]$. Many thermodynamics cycles are applicable in the temperature below $350{ }^{\circ} \mathrm{C}$, like the $\mathrm{CO}_{2}$ transcritical power cycle, Organic Rankine Cycle (ORC) and Trilateral Flash Cycle (TFC), instead of high-temperature steam Rankine Cycle (RC) [1, 3-5]. CO 2 has a low critical temperature, which makes it appropriate for utilizing a low heat source - geothermal $[6,7] . \mathrm{CO}_{2}$ power cycles are widely used in air conditioning, heat pumps, refrigerating systems, and power cycles [8-11]. $\mathrm{CO}_{2}$ power cycle can be used to utilize solar heat, but due to the weather-dependence of this source, a heat storage system is required to provide continuous heating. Also, integration of the absorption refrigeration system with reheat transcritical power cycle leads to improve the efficiency and maintain stable productivity by keeping the low condensation temperature at all different weather conditions. Using the compressed air energy storage help to overcome the decrease or interruption for solar energy and improves the technical flexibility in solar thermal power and storage $[12,13]$. Using a regenerative heat exchanger (recuperator) in the $\mathrm{CO}_{2}$ transcritical cycle improves overall net power and overall thermal efficiency [14]. At the low and high heat source temperature, the transcritical $\mathrm{CO}_{2}$ power cycle using mixed $\mathrm{CO}_{2}$ is better than the cycle that using pure carbon dioxide, thermodynamically, and exergo-economically. It has been shown by analyzing 
binary mixtures of carbon dioxide with other refrigerants (R32, R1270, R161, R1234yf, R1234ze, R152a), and alkanes (butane, pentane, propane, isobutene or isopentane) that the highest exergy efficiency and the lower levelized cost per unit of exergy product was with $\mathrm{CO}_{2}$ /propane at the high-temperature heat source. At lower heat source temperature, the highest exergy efficiency was with $\mathrm{CO}_{2} / \mathrm{R} 32$, and the lowest levelized cost per unit of exergy product was with $\mathrm{CO}_{2} / \mathrm{R} 161$ [15]. With $\mathrm{CO}_{2}$ mixtures that consist of binary mixture of $\mathrm{CO}_{2}$ with one of these refrigerants (R152a, R161, R290, R1234yf, R1234ze, and R1270) with a transcritical power cycle at geothermal water temperature between 100 and $150{ }^{\circ} \mathrm{C}$ and temperature of cooling tower $10-30{ }^{\circ} \mathrm{C}$, it has been observed that the better thermal performance and economic performance was with $\mathrm{R} 161 / \mathrm{CO}_{2}$, while the $\mathrm{R} 290 / \mathrm{CO}_{2}$ was the worst due to low thermal performance. The cost per net power reduction, decrease of operating pressure and extension of the range of condensing temperature, all these occur with the blends of $\mathrm{CO}_{2}$ more than the $\mathrm{CO}_{2}$ in a pure state. At the low cooling water temperature, $\mathrm{R} 152 \mathrm{a} / \mathrm{CO}_{2}$ mixed working fluid is not suitable with the proposed system [16]. The comparison between basic, recuperator, reheat, and regenerative systems for transcritical $\mathrm{CO}_{2}$ power cycle demonstrated that reheat transcritical $\mathrm{CO}_{2}$ cycle is the best one, concerning thermoeconomic performance, and reheat system showed an increase in net power produced, energy efficiency, and efficiency of exergy compared the basic transcritical $\mathrm{CO}_{2}$ cycle while the total investment cost is higher for reheat system due to largest heat transfer area [17]. Condensing is one of the problems facing the conventional $\mathrm{CO}_{2}$ trans- and subcritical $\mathrm{CO}_{2}$ power cycles by using traditional water cooling, but with self-condensing, the $\mathrm{CO}_{2}$ carbon dioxide transcritical power cycle overcome this problem and can operate well with the cooling water as warm as $30{ }^{\circ} \mathrm{C}[18$, 19]. The $\mathrm{CO}_{2}$ transcritical power cycle has a better economic performance than the organic Rankine cycle in terms of cost per net power output and under a certain turbine inlet pressure. The cost per net power output in the regenerative $\mathrm{CO}_{2}$ transcritical power cycle is even lower than that of the basic $\mathrm{CO}_{2}$ transcritical power cycle, that which observed by analyzing the organic Rankine cycle and $\mathrm{CO}_{2}$ transcritical cycle with a geothermal heat source and different working fluids for example isobutane, R123, pentane R245fa [20].

The subcritical $\mathrm{CO}_{2}$ power cycle $\left(\mathrm{CO}_{2}\right.$ Rankine cycle) can use the ambient temperature or low-temperature geothermal as a heat source; these two sources are classified as a low enthalpy source [21]. To properly characterize the transcritical cycle, it requires a deep knowledge of the subcritical carbon cycle [22]. When the ambient temperature or some other source with similar temperature (for example, thermal water not above $35-40{ }^{\circ} \mathrm{C}$ ) are used as a heat source, then - depending on the weather conditions - transcritical cycles might shift to the sub-critical region (i.e., the maximum temperature will be below the critical temperature of $\mathrm{CO}_{2}$ ). In that case, it is better to use a subcritical $\mathrm{CO}_{2}$ cycle. Still, engineers should know that there is a narrow temperature range near to the critical temperature, where the thermodynamic efficiency has inverse maximum cycle temperature dependence. Therefore, there is a temperature range, which should be avoided during this application. The aim of the study is to demonstrate to engineers and researchers that the efficiency does not always increase with increasing heat source temperature, but sometimes the increasing of the heat source temperature close to the critical temperature leads to decreasing the efficiency. That can also happen with other thermodynamics cycles using various working fluids, for example Rankine cycle and organic Rankine cycle. This study focused on the subcritical $\mathrm{CO}_{2}$ power cycle with low heat source temperature close to the critical points.

\section{METHODS}

The water and some organic materials are working fluids used in the power plants using steam and organic Rankine cycles, respectively. In contrast, in the $\mathrm{CO}_{2}$ power cycle, carbon dioxide is used as a working fluid. The subcritical $\mathrm{CO}_{2}$ power cycle operates under temperature and pressure not exceeding the critical point for $\mathrm{CO}_{2}$. Therefore, the low heat source temperature, like ambient temperature $\left(T_{a m b}\right)$ or geothermal, is sufficient for the subcritical $\mathrm{CO}_{2}$ power cycle. The ideal cycle was used in this study that was an isobaric process at the heat exchangers and isentropic steps at the expansion and compression.

\subsection{Components and processes of $\mathrm{CO}_{2}$ power cycle}

The subcritical $\mathrm{CO}_{2}$ cycle is very similar to the simple steam Rankine cycle; therefore it is called the $\mathrm{CO}_{2}$ Rankine cycle. Evaporator, turbine, condenser, and pump are demand to configuration the $\mathrm{CO}_{2}$ power cycle, as it is shown in Fig. 1a. The $T-s$ diagram shows the processes of the $\mathrm{CO}_{2}$ power cycle in Fig. 1b. The $\mathrm{CO}_{2}$ compressed from point 1 to point 2 by a pump in an isentropic process. A slight increase in temperature occurs, together with the rise of the pressure. Then, $\mathrm{CO}_{2}$ enters the heat exchanger (sometimes called evaporator) at point 2 ; here, in the initial part, the temperature will increase. Then, after reaching the boiling temperature for the given pressure, evaporation happens, even the total mass of the fluid reaches a vapor state (point 3). At point 3 , the fluid is in high pressure and high temperature saturated vapor state. Here, the working fluid enters the turbine (or expander) with high pressure and temperature to produce the mechanical work by expansion between points 3 and 4. During this process (taken as ideal adiabatic, i.e., isentropic one) pressure and temperature of the working fluid is decreased. In stage 4 , the fluid is in a lowenthalpy, low-temperature, low-pressure saturated vapor state. Between points 4 and 1, part of the heat is removed from the system isobarically in a second heat exchanger, called condenser, causing complete condensation from saturated steam to saturated liquid state in order to start a new cycle. 

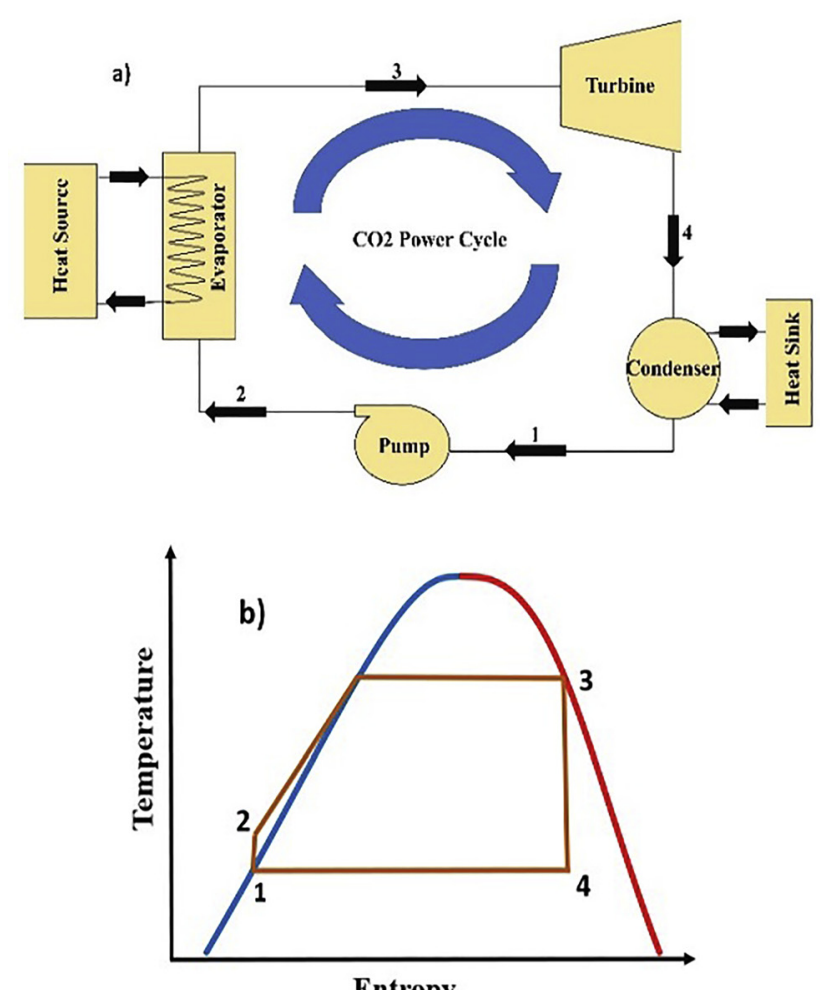

Entropy

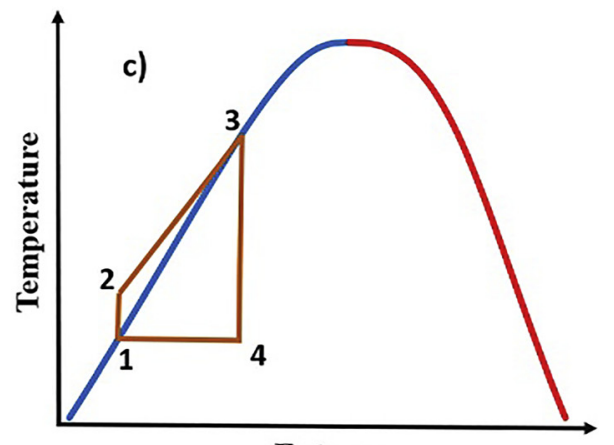

Entropy

Fig. 1. Schematic diagram for $\mathrm{CO}_{2}$ power cycle, a) Main components of cycle, b) $T-s$ diagram for $\mathrm{CO}_{2}$ power cycle, and c) $T-s$ diagram for TFC cycle

There is a slightly different cycle, called TFC; it is characterized by its simplicity. Heat addition terminates, when the saturated liquid state reached (point 3, Fig. 2). In this way, the fluid volume between points 2 and 3 is not significantly different, and therefore the heat exchanged for TFC can be simpler, than for ORC. In general, the process 1-2-3-4 is similar to the $\mathrm{CO}_{2}$ cycle used in the study. The two differences are the lack of evaporation in the 'evaporator' and the "wet expansion" (i.e., expansion starting from

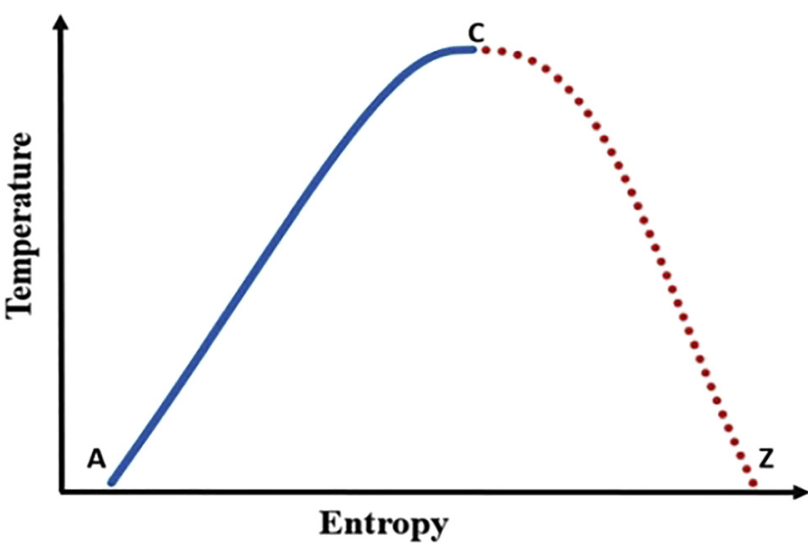

Fig. 2. T-s diagram for carbon dioxide as wet working fluid with characteristic points (see in text)

the liquid state) in the expander [23]. The difference can be seen in detail in Fig. $1 \mathrm{~b}$ and $\mathrm{c}$.

\subsection{Characteristics of $\mathrm{CO}_{2}$ as working fluid}

Due to the thermal stability, the $\mathrm{CO}_{2}$ is one of the natural working fluids considered suitable for the refrigeration and power cycles, also; it has significant advantages compared to other working fluids that lack whole or part of these characteristics, which include physical, chemical, environmental, and economic features. There are some crucial factors that must be considered when selecting a working fluid, or it characterizes the working fluids, for chemically factors like non-flammability, low toxicity; physical factors, like high critical pressure $\left(P_{c r}\right)$, low critical temperature, low boiling point $\left(B_{p}\right)$, and good heat transfer; the environmental ones, like low Global Warming Potential (GWP), low OzoneDepleting Potential (ODP), and environmentally friendliness (very safe to use); and finally, low cost as the economic factor. Carbon dioxide is one of the liquids whose properties satisfy the above-mentioned characteristics; additionally, it is a "natural" fluid. The $\mathrm{CO}_{2}$ properties and American Society of Heating, Refrigerating and Air-Conditioning Engineers (ASHRAE) for $\mathrm{CO}_{2}$, are shown in Table 1 . The $\mathrm{CO}_{2}$ can be used in all types of $\mathrm{CO}_{2}$ cycles like subcritical, transcritical, supercritical; also, it can be used as pure fluid as well as in mixtures with other working fluids especially with hydrocarbons, especially because of its ability to reduce the flammability of hydrocarbons while preserving all the other desired thermodynamic properties [24]. According to the traditional working fluid classification, $\mathrm{CO}_{2}$ is a wet working fluid; in the novel classification, it belongs to the so-called ACZ class [25].

Table 1. Properties of carbon dioxide

(Source: on the basis of [26])

\begin{tabular}{lcccccccccc}
\hline Type & Category & $\begin{array}{c}\text { ASHRAE } \\
\text { NO. }\end{array}$ & Formula & $\begin{array}{c}\text { ASHRAE level for } \\
\text { safety }\end{array}$ & ODP & GWP & $\begin{array}{c}\text { Critical } \\
\text { temperature }[\mathrm{K}]\end{array}$ & $\begin{array}{c}\text { Critical Pressure } \\
{[\mathrm{MPa}]}\end{array}$ & $\begin{array}{c}\text { Boiling Point } \\
{[\mathrm{K}]}\end{array}$ \\
\hline Wet & ACZ & 744 & $\mathrm{CO}_{2}$ & Al & 0 & 1 & 304.1282 & 7.3773 & 194.75 \\
\hline
\end{tabular}




\subsection{Thermodynamic analysis}

A calculation was performed to find the efficiency of the $\mathrm{CO}_{2}$ power cycle with the temperature variation of the heat source by using the MATLAB software and data from the NIST webbook [27]. On the T-s diagram of $\mathrm{CO}_{2}, \mathrm{~A}$ and $\mathrm{Z}$ marks the minimum temperature for liquid and vapor phases, and $\mathrm{C}$ is the critical point, as shown in Fig. 2. The blue solid line represents the saturated liquid state, and the red dashed line represents the saturated vapor state. General equations were used. The efficiency was calculated by

$$
\eta=\frac{\left(h_{3}-h_{4}\right)-\left(h_{2}-h_{1}\right)}{\left(h_{3}-h_{2}\right)}
$$

where the $\left(h_{3}-h_{4}\right),\left(h_{2}-h_{1}\right)$, and $\left(h_{3}-h_{2}\right)$, are the difference in enthalpy at the turbine, pump, and evaporator respectively, and the enthalpy and other data values as entropy, pressure, and dryness fraction found by NIST webbook.

In this study, some assumptions and parameters applied like the steady-state of the operation cycle, and ignored the pressure losses during the flow. At the saturated vapor phase, the working fluid entering the turbine, and the inlet pressure changes based on the increasing the heat source temperature, while in the TFC cycle, the working fluids enter the turbine at the saturated liquid. Depended on the condenser temperature and dryness fraction, the working fluid enters the condenser then leaves it at the saturated liquid. Ten thousand steps, using different temperature pairs were used in this study (with 1,000 readings for each curve, 500 for the $\mathrm{CO}_{2}$ cycle, and 500 for the TFC cycle). The condenser line, green solid line is at low temperature, for example, $217 \mathrm{~K}$, and all the horizontal lines above the condenser line, green solid line are the evaporator lines (increase with increasing heat source temperature starting from orange dot line to dark blue long dash line), up to the critical point. First, the 1-2-3-4 cycle efficiency was calculated then evaporation temperature was shifted to a higher value, while the condensation temperature was kept and the efficiency of the new cycle (1-2a-3a-3b) was determined. The process continued upwards, to the vicinity of the critical temperature (see cycle $1-2 \mathrm{~d}-3 \mathrm{~d}-4 \mathrm{~d}$ ) as it is shown in Fig. 3. In the next step, a new (increased) condenser temperature was taken $(238 \mathrm{~K}$ instead of $217 \mathrm{~K}$ green solid line shifts upward). For this new value, efficiencies related to changing evaporation temperature (orange dot, gold dash, purple long dash dot, blue long dash dot dot, and dark blue long dash lines), were also calculated. In the following steps, the process was repeated with new condenser temperatures. Finally, obtained the whole set of efficiency

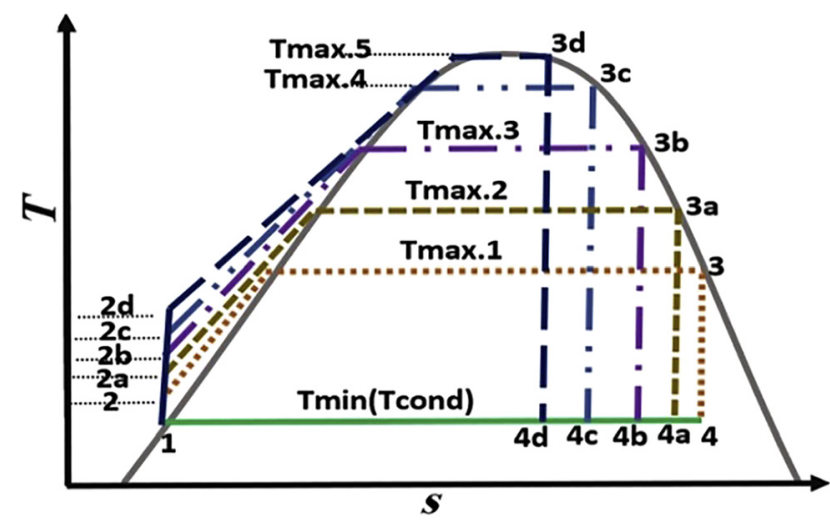

Fig. 3. The procedure of the calculation on a $T-s$ diagram for $\mathrm{CO}_{2}$ power cycle

values for various condensation and evaporation temperature pairs from $217 \mathrm{~K}$ to the critical temperature was obtained. The same processes were applied for the TFC cycle, except that the entering parameter in the turbine would be saturated liquid, as it is shown in Fig. 4. All boundary conditions are shown in Table 2.

\section{RESULTS AND DISCUSSION}

Carbon dioxide can be applied as working fluid in refrigeration cycles as well as in and power cycles. This study focused on the sub-critical $\mathrm{CO}_{2}$ power cycle by utilizing lowtemperature heat sources for example ambient temperature or geothermal one with several of condenser temperatures. In general, the efficiency increases with increasing the heat

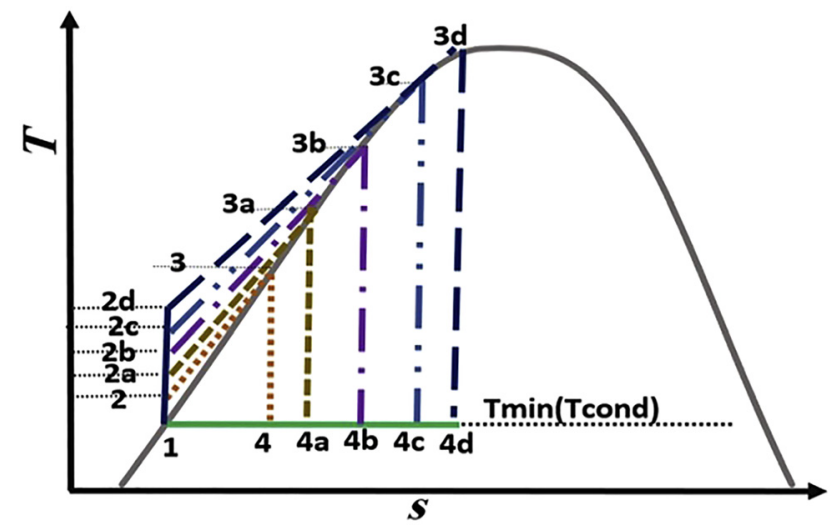

Fig. 4. The procedure of the calculation on a $T-s$ diagram for TFC power cycle

Table 2. The boundary conditions

\begin{tabular}{lccccc}
\hline Run & Heat source temperature $[\mathrm{K}]$ & Heat sink temperature $[\mathrm{K}]$ & Run & Heat source temperature $[\mathrm{K}]$ & Heat sink temperature[K] \\
\hline 1 & 217 to $T_{c r}$ & 217 & 6 & 278 to $T_{c r}$ & 278 \\
2 & 238 to $T_{c r}$ & 238 & 7 & 284 to $T_{c r}$ & 284 \\
3 & 252 to $T_{c r}$ & 252 & 8 & 290 to $T_{c r}$ & 290 \\
4 & 266 to $T_{c r}$ & 266 & 9 & 296 to $T_{c r}$ & 296 \\
5 & 272 to $T_{c r}$ & 272 & 10 & 302 to $T_{c r}$ & 302 \\
\hline
\end{tabular}


source temperature. It has been found in sub-critical $\mathrm{CO}_{2}$ cycles (and can be generalized to all cycles having similar, ACZ-type $T-s$ diagram) that while this increase is usually true, choosing the maximal cycle temperature close to the critical point, inverse dependency can be seen a narrow, but definitely non-zero temperature range. In contrary, for TFC, the maximum efficiency was at the critical temperature as it is shown in Fig. 5; the upper curves represent the efficiency values of $\mathrm{CO}_{2}$ power cycles and the lower curves for TFC cycles. For example, the first curve for $\mathrm{CO}_{2}$ and TFC, the range of evaporator temperature (heat source temperature) between 217 and $304.1282 \mathrm{~K}$, calculated point by point with an increment equal to (total temperature range)/500, with fixed condenser temperature $217 \mathrm{~K}$. For the next curve, the condenser temperature was increased, and the calculation was repeated.

Separate lines in Fig. 6 represent the variation of efficiency for $\mathrm{CO}_{2}$ power cycle with increasing heat source temperature and with fixed condenser temperature (represented by the lowest temperature value on each curve), the efficiency increases for a while with increasing heat source temperature, but then a maximum appears, close, but definitely below the critical temperature, followed by an efficiency decrease, supported by results obtained with other working fluids for ORC and TFC [28]. The red dots (diamond marker) show the positions of the efficiency

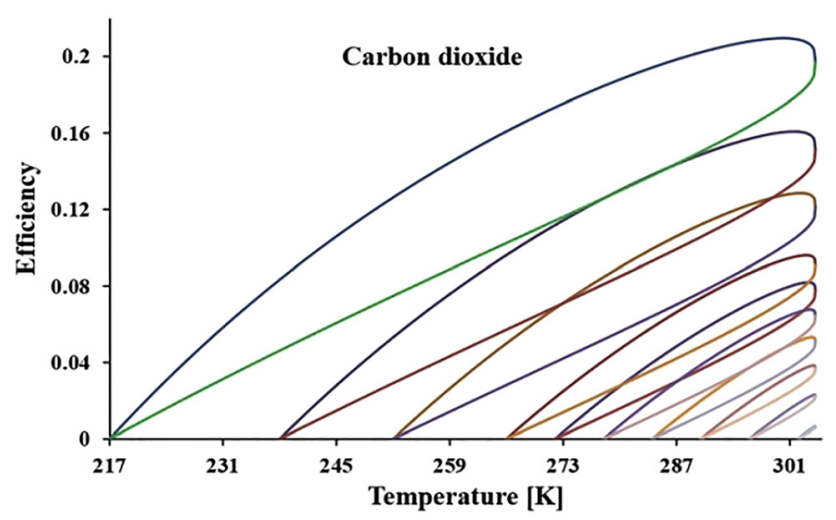

Fig. 5. Efficiency variation with heat source temperature for $\mathrm{CO}_{2}$ and TFC cycle

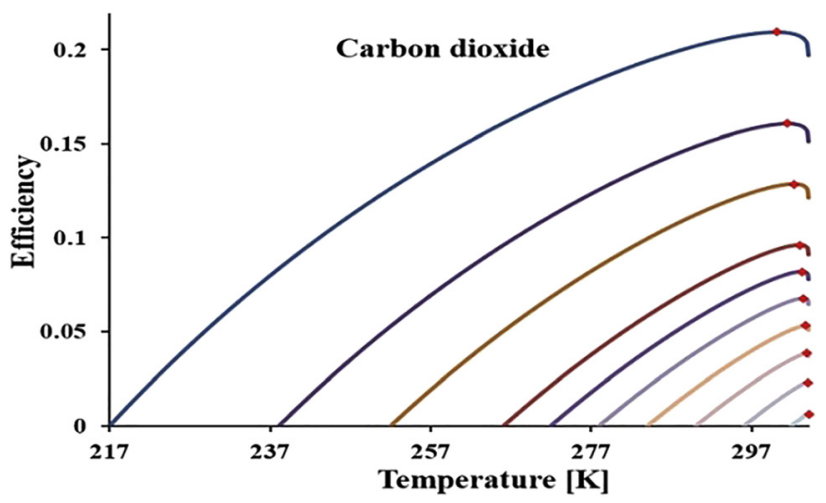

Fig. 6. Maximum efficiency (red spots) for $\mathrm{CO}_{2}$ power cycle maximum, which is always below the critical temperature (located at the end of the curves), also the dots showing that maximum efficiency shifted close to the critical temperature with a minimum value of efficiency in the and the maximum condenser temperature $302 \mathrm{~K}$. However, even this new maximum is definitely below (although closer, than the previous maximum) the critical point. It is approaching the critical temperature and its value is very small; 0.066 , located at $304.10 \mathrm{~K}$ (while the critical temperature is $304.1282 \mathrm{~K}$ ). Figure 7 shows efficiency for the $\mathrm{CO}_{2}$ cycle and TFC cycle in the range where this maximum appears, up to the critical temperature. The curve represents the case with condenser temperature located at $217 \mathrm{~K}$, and showing that the two efficiency curves meet at one point at the critical temperature. Figure 8 shows the efficiency values at the maximum, together with the temperature of this maximum and how it decreases with increasing condenser temperature.

\section{CONCLUSION}

The $\mathrm{CO}_{2}$ power cycle has reasonably good efficiency operating with low-temperature heat sources. It uses $\mathrm{CO}_{2}$ as a working fluid, with suitable physical, chemical, environmental, and economic characteristics, compared to other working fluids. It has been known to researchers and

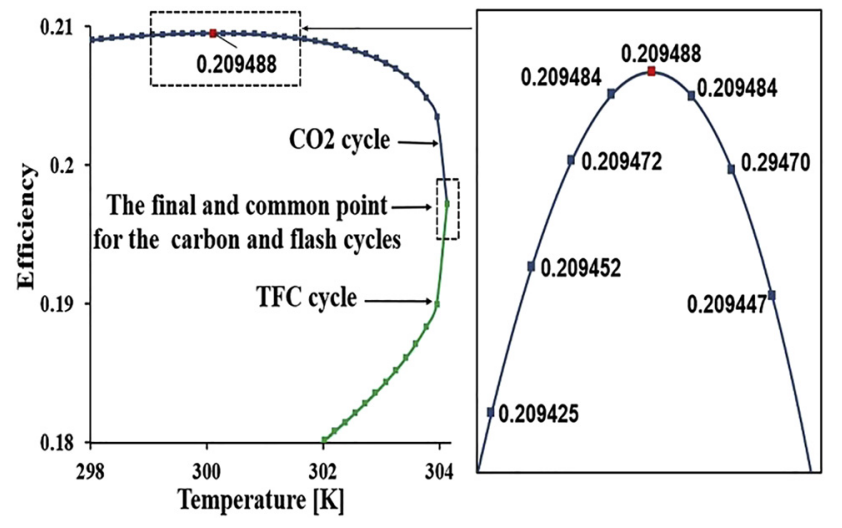

Fig. 7. Efficiency for $\mathrm{CO}_{2}$ and $\mathrm{TFC}$ at Condenser temperature $217 \mathrm{~K}$

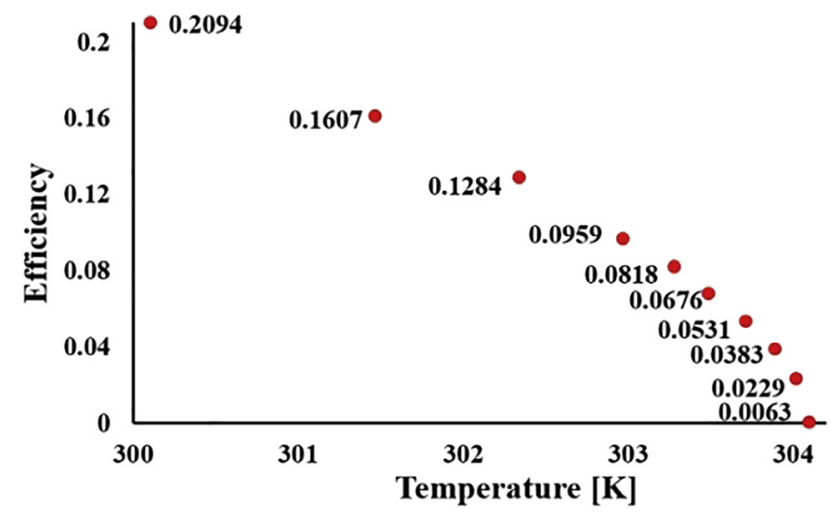

Fig. 8. The shift of the efficiency-maxima 
engineers that for thermodynamic cycles the efficiency increases with the increase in the source temperature. This study showed that the efficiency of the cycle does not always increase with increasing maximal cycle temperature (and heat source temperature); close to the critical temperature; on the contrary, it reduces efficiency. It means that an efficiency maximum can exist, and the existence of this maximum should be considered upon designing subcritical $\mathrm{CO}_{2}$ Rankine cycles with maximal cycle temperature close to the critical one. In some cases (like with solar heat), the increase of the heat source temperature goes together with the increase in installation costs. This cost increase is justified only when it is associated with proper efficiency increase; in the vicinity of the critical temperature, it is not justified. The maximum of the efficiency goes closer to the critical temperature as the condenser temperature increased, while its absolute value decreases. Also, it has been shown that the efficiency of the subcritical $\mathrm{CO}_{2}$ power cycle higher than the efficiency of TFC and their efficiency equal at the critical point.

\section{ACKNOWLEDGEMENTS}

This work was performed in the frame of the FIEK_16-12016-0007 project, implemented with the support provided from the National Research, Development and Innovation Fund of Hungary, financed under the FIEK_16 funding scheme. Part of the research reported in this paper and carried out at BME has been supported by the NRDI Fund (TKP2020 NC, Grant No. BME-NC) based on the charter of bolster issued by the NRDI Office under the auspices of the Ministry for Innovation and Technology.

\section{REFERENCES}

[1] E. Cayer, N. Galanis, M. Desilets, H. Nesreddine, and P. Roy, "Analysis of a carbon dioxide transcritical power cycle using a low temperature source," Appl. Energ., vol. 86, no. 7-8, pp. 1055-1063, 2009.

[2] Y. T. Ge, L. Li, X. Luo, and S. A. Tassou, "Performance evaluation of a low-grade power generation system with $\mathrm{CO}_{2}$ transcritical power cycles," Appl. Energ., vol. 227, pp. 220-230, 2018.

[3] L. Li, T. Ge, X. Luo, and S. A. Tassou, "Experimental investigations into power generation with low grade waste heat and R245fa Organic Rankine Cycles (ORCs)," Appl. Therm. Eng., vol. 115, pp. 815-824, 2017.

[4] C. Zamfirescu and I. Dincer, "Thermodynamic analysis of a novel ammonia-water trilateral Rankine cycle," Thermochim. Acta, vol. 477, no. 1-2, pp. 7-15, 2008.

[5] O. Al-Oran and F. Lezsovits, "Enhance thermal efficiency of parabolic trough collector using Tungsten oxide/Syltherm 800 nanofluid," Pollack Period., vol. 15, no. 2, pp. 187-198, 2020.

[6] S. Mondal and S. De, "Transcritical $\mathrm{CO}_{2}$ power cycle - Effects of regenerative heating using turbine bleed gas at intermediate pressure," Energy, vol. 87, pp. 95-103, 2015.
[7] C. Tonkó, "Criterion for the discharge of geothermal waste water into surface water sources in Hungary," Pollack Period., vol. 7, no. 2, pp. 129-138, 2012.

[8] X. Lei, R. Peng, Z. Guo, H. Li, K. Ali, and X. Zhou, "Experimental comparison of the heat transfer of carbon dioxide under subcritical and supercritical pressures," Int. J. Heat Mass Transf., vol. 152, Paper no. 119562, 2020.

[9] H. Tuo, "Analysis of a reheat carbon dioxide transcritical power cycle using a low temperature heat source," in ASME 2011 International Conference on Environmental Engineering and Applications, Parts A and B, Denver, Colorado, USA, November 11-17, 2011, 2011, pp. 219-225.

[10] H. Chen, D. Y. Goswami, and E. K. Stefanakos, "A review of thermodynamic cycles and working fluids for the conversion of low-grade heat," Renew. Sustain. Energ. Rev., vol. 14, no. 9, pp. 3059-3067, 2010.

[11] P. Dutta and P. Kumar, "Supercritical carbon dioxide-based power cycles," in Encyclopedia of Sustainable Technologies, M. A. Abraham (ed.) Elsevier, pp. 419-428, 2017.

[12] A. A. AlZahrani and I. Dincer, "Thermodynamic analysis of an integrated transcritical carbon dioxide power cycle for concentrated solar power systems," Sol. Energ., vol. 170, pp. 557-567, 2018.

[13] J. Meng, M. Wei, P. Song, R. Tian, L. Hao, and S. Zheng, "Performance evaluation of a solar transcritical carbon dioxide Rankine cycle integrated with compressed air energy storage," Energy Convers. Manag., vol. 215, Paper no. 112931, 2020.

[14] C. Wu, S. S. Wang, and J. Li, "Parametric study on the effects of a recuperator on the design and off-design performances for a $\mathrm{CO}_{2}$ transcritical power cycle for low temperature geothermal plants," Appl. Therm. Eng., vol. 137, pp. 644-658, 2018.

[15] J. Xia, J. Wang, G. Zhang, J. Lou, P. Zhao, and Y. Dai, "Thermoeconomic analysis and comparative study of transcritical power cycles using $\mathrm{CO}_{2}$-based mixtures as working fluids," Appl. Therm. Eng., vol. 144, pp. 31-44, 2018.

[16] C. Wu, S. S. Wang, X. Jiang, and J. Li, “Thermodynamic analysis and performance optimization of transcritical power cycles using $\mathrm{CO}_{2}$-based binary zeotropic mixtures as working fluids for geothermal power plants," Appl. Therm. Eng., vol. 115, pp. 292-304, 2017.

[17] F. Meng, E. Wang, B. Zhang, F. Zhang, and C. Zhao, "Thermoeconomic analysis of transcritical $\mathrm{CO}_{2}$ power cycle and comparison with Kalina cycle and ORC for a low-temperature heat source,” Energ. Convers. Manag., vol. 195, pp. 1295-1308, 2019.

[18] L. Pan, B. Li, W. Shi, and X. Wei, "Optimization of the selfcondensing $\mathrm{CO}_{2}$ transcritical power cycle using solar thermal energy," Appl. Energ., vol. 253, Paper no. 113608, 2019.

[19] L. Pan, W. Shi, X. Wei, T. Li, and B. Li, "Experimental verification of the self-condensing $\mathrm{CO}_{2}$ transcritical power cycle," Energy, vol. 198, Paper no. 117335, 2020.

[20] M. Li, J. Wang, S. Li, X. Wang, W. He, and Y. Dai, "Thermo-economic analysis and comparison of a $\mathrm{CO}_{2}$ transcritical power cycle and an organic Rankine cycle," Geothermics, vol. 50, pp. 101-111, 2014.

[21] W. Xia, Y. Huo, Y. Song, J. Han, and Y. Dai, "Off-design analysis of a $\mathrm{CO}_{2}$ Rankine cycle for the recovery of LNG cold energy with ambient air as heat source," Energ. Convers. Manag., vol. 183, pp. 116-125, 2019.

[22] L. L. Shao and C. L. Zhang, "Thermodynamic transition from subcritical to transcritical $\mathrm{CO}_{2}$ cycle," Int. J. Refrig., vol. 64, pp. 123-129, 2016. 
[23] A. R. Imre and A. Groniewsky, "Various ways of adiabatic expansion in Organic Rankine Cycle (ORC) and in Trilateral Flash Cycle (TFC)," Zeitschrift Phys. Chem., vol. 233, no. 4, pp. 577-594, 2019.

[24] P. Kumar and K. Srinivasan, "Carbon dioxide based power generation in renewable energy systems," Appl. Therm. Eng., vol. 109, pp. 831-840, 2016.

[25] G. Györke, U. K. Deiters, A. Groniewsky, I. Lassu, and A. R. Imre, "Novel classification of pure working fluids for organic Rankine cycle," Energy, vol. 145, pp. 288-300, 2018.
[26] Y. Chen, Novel Cycles Using Carbon Dioxide as Working Fluid. Stockholm, KTH: School of Industrial Engineering and Management. 2006.

[27] NIST Chemistry Webbook. NIST Standard Reference Database, Number 69, 2018. [Online]. Available: https://webbook.nist.gov/ chemistry/. Accessed: Feb. 1, 2020.

[28] A. M. Ahmed, L. Kondor, and A. R. Imre, "Thermodynamic efficiency maximum of simple organic Rankine cycles," Energies, vol. 14, no. 2, pp. 307-323, 2021. 